\title{
Comparison of Separation Performance of a Structured Packed Column with a Tray-Type Column for $\mathrm{H}_{2} \mathrm{~S}$ and $\mathrm{CO}_{2}$
}

\author{
M. Baniadam, J. Fathikalajahi* and M.R. Rahimpour \\ Chemical and Petroleum Engineering Department, Shiraz University, Shiraz - Iran \\ e-mail: baniadam@shirazu.ac.ir -fathi@shirazu.ac.ir -rahimpour@shirazu.ac.ir \\ * Corresponding author
}

\begin{abstract}
Résumé - Comparaison des performances de séparation d'une colonne à garnissage structurée avec celles d'une colonne à plateaux pour $\mathrm{l}^{\prime} \mathrm{H}_{2} \mathrm{~S}$ et le $\mathbf{C O}_{2}-\mathrm{L}$ 'absorption de gaz acides, $\mathrm{H}_{2} \mathrm{~S}$ et $\mathrm{CO}_{2}$, par la méthyldiéthanolamine dans une colonne à garnissage structure équipée du Montz-Pak A3-500 a été modélisée mathématiquement. Les dimensions des canaux ainsi que leur nombre et le modèle d'écoulement du film liquide sont similaires à ceux des travaux de Shilkin. Les équations de transfert de la chaleur et de la masse sont dérivées pour le film liquide de réaction et le gaz qui s'écoule à contrecourant dans la colonne. La répartition de la concentration est calculée sur tout le film liquide en mouvement et aucune zone présentant des conditions de concentration équilibrée n'est prise en compte dans le liquide réactif. Les résultats du modèle pour la colonne structurée montrent de meilleures performances d'absorption du $\mathrm{H}_{2} \mathrm{~S}$ qu'avec une colonne à plateaux dans les mêmes conditions. Les résultats obtenus par le modèle indiquent une répartition appréciable de la répartition de la concentration et de la température le long de la colonne.
\end{abstract}

Abstract - Comparison of Separation Performance of a Structured Packed Column with a Tray-Type Column for $\mathrm{H}_{2} \mathrm{~S}$ and $\mathrm{CO}_{2}-$ Absorption of acid gases, $\mathrm{H}_{2} \mathrm{~S}$ and $\mathrm{CO}_{2}$, by methyl diethanol amine in a structured packed column equipped with Montz-Pak A3-500 was mathematically modeled. The dimensions of the channels as well as their number and liquid film flow model are similar to the Shilkin's work. Heat and mass transfer equations are derived for reacting liquid film and gas flowing countercurrently into the column. Concentration distribution is calculated across the moving liquid film and no zone with equilibrium concentration conditions is considered in the reacting liquid. The results of the model for the structured column show a better performance for $\mathrm{H}_{2} \mathrm{~S}$ absorption compared with a tray column operating in the same conditions. The results obtained by the model indicate appreciable distribution of concentration and temperature along the column. 


\section{NOMENCLATURE}

$a_{e} \quad$ effective mass transfer area to packing volume $\left(\mathrm{m}^{2} / \mathrm{m}^{3}\right)$

$a_{t} \quad$ interfacial area to packing volume $\left(\mathrm{m}^{2} / \mathrm{m}^{3}\right)$

A coefficient defined in Equation (4)

$b \quad$ width of corrugation normal to column axis (m)

$b_{0} \quad$ width of corrugation normal to direction of flow (m)

$B$ coefficient defined in Equation (4)

$C$ coefficient defined in Equation (4)

C concentration (mole $/ \mathrm{m}^{3}$ )

$C A_{1}$ concentration of $\mathrm{CO}_{2}$ in liquid $\left(\mathrm{mole} / \mathrm{m}^{3}\right.$ )

$\mathrm{CA}_{2}$ concentration of $\mathrm{H}_{2} \mathrm{~S}$ in liquid $\left(\mathrm{mole} / \mathrm{m}^{3}\right.$ )

$C B_{2}$ concentration of MDEA in liquid (mole $/ \mathrm{m}^{3}$ )

$C E_{2}$ concentration of $\mathrm{HCO}_{3}{ }^{-}$in liquid $\left(\mathrm{mole} / \mathrm{m}^{3}\right)$

$\mathrm{CE}_{3}$ concentration of $\mathrm{HS}^{-}$in liquid (mole $/ \mathrm{m}^{3}$ )

$\mathrm{CF}_{2}$ concentration of $\mathrm{MDEAH}^{+}$in liquid $\left(\mathrm{mole} / \mathrm{m}^{3}\right)$

$C_{p} \quad$ specific heat $(\mathrm{J} / \mathrm{mol} . \mathrm{K})$

$d_{h} \quad$ hydraulic diameter of channels (m)

$D$ diffusion coefficient $\left(\mathrm{m}^{2} / \mathrm{s}\right)$

$\bar{D}$ molar average diffusion coefficient $\left(\mathrm{m}^{2} / \mathrm{s}\right)$

$D_{\text {pac }}$ packing diameter (m)

$F \quad$ mole flow rate $(\mathrm{kmole} / \mathrm{h})$

$g \quad$ gravity acceleration $\left(\mathrm{m} / \mathrm{s}^{2}\right)$

$h \quad$ corrugation height $(\mathrm{m})$

$h_{i}^{e x} \quad$ excess molar enthalpy $(\mathrm{J} / \mathrm{mole})$

$h_{i}^{i s} \quad$ ideal solution molar enthalpy $(\mathrm{J} / \mathrm{mole})$

$\bar{h}_{i}^{l i q}$ partial molar enthalpy of component $i$ in liquid (J/mole)

$K$ reaction equilibrium constant

$k_{L} \quad$ mass transfer coefficient $(\mathrm{m} / \mathrm{s})$

$L$ mole flow rate of liquid (mole/s)

$L \quad$ height of packing segment (m)

$\dot{m}$ mass flow rate $(\mathrm{kg} / \mathrm{s})$

$\bar{M} \quad$ average molecular weight

$P \quad$ pressure $(\mathrm{Pa})$

$q \quad$ volume flow rate $\left(\mathrm{m}^{3} / \mathrm{s}\right)$

$R \quad$ gas constant ( $\mathrm{J} /$ mole. $\mathrm{K})$

$R h \quad$ hydraulic radius of channels (m)

width of corrugation side normal to column axis (m) width of corrugation side normal to direction of flow (m)

$S_{e} \quad$ packing effective (wetted) mass transfer area $\left(\mathrm{m}^{2}\right)$

$S_{t} \quad$ packing geometric (installed) area $\left(\mathrm{m}^{2}\right)$

$T$ temperature (K)

$u \quad$ velocity $(\mathrm{m} / \mathrm{s})$

v velocity vector $(\mathrm{m} / \mathrm{s})$
$V \quad$ mole flow rate of gas (mole/s)

$w_{G} \quad$ width of total area in a packing cross-section (m)

$w_{L} \quad$ width of wetted area in a packing cross-section (m)

$x \quad$ Cartesian coordinate, mole fraction of liquid

$y \quad$ Cartesian coordinate, mole fraction of gas

$z \quad$ mixing length $(\mathrm{m})$

\section{Greek letters}

$\alpha \quad$ gravity flow angle $\left({ }^{\circ}\right)$

$\gamma \quad$ angle between column axis and flow direction $\left({ }^{\circ}\right)$

$\gamma \quad$ activity coefficient

$\delta \quad$ film thickness (m)

$\varepsilon \quad$ porosity of column

$\lambda$ heat diffusivity $\left(\mathrm{m}^{2} / \mathrm{s}\right)$

$\mu \quad$ dynamic viscosity $(\mathrm{kg} / \mathrm{ms})$

$\rho \quad$ density $\left(\mathrm{kg} / \mathrm{m}^{3}\right)$

$\varphi \quad$ corrugation inclination angle (with respect to column axis) $\left(^{\circ}\right)$

\section{Subscripts}

$G \quad$ referring to gas

in entrance flow

$L \quad$ referring to liquid

out exit flow

rxn reaction

\section{Superscripts}

$a q$ aqueous

$f$ formation

$g$ referring to gas

ig ideal gas

is ideal solution

$l \quad$ referring to liquid

lv liquid to vapor

ref reference state

sat saturation

\section{INTRODUCTION}

Natural gas is considered sour if $\mathrm{H}_{2} \mathrm{~S}$ and $\mathrm{CO}_{2}$ are present in more than standard amounts in the gas. In this case, before the gas can be utilized, $\mathrm{H}_{2} \mathrm{~S}$ and $\mathrm{CO}_{2}$ must be removed and this is called gas sweetening. The gas is usually sweetened by absorption of the $\mathrm{H}_{2} \mathrm{~S}$ and $\mathrm{CO}_{2}$ into an amine solution in a classical sieve plate column. Natural gas is one of the sources 
of relatively clean energy and the demand for it is increasing rapidly. The effective purification of this energy source requires more sophisticated equipment since a huge amount of gas should be processed daily. The new generation of columns, called structured packed beds, which offer better mass transfer and relatively low pressure drop, are one such type of equipment [1-9]. Mathematical modeling of absorption of acid gas into MDEA (methyl diethanol amine) in structured packing requires a comprehensive model for liquid and gas flow in the bed. Localization of boundaries regarding the two phases, except for simple motions such as films, jets, etc. is practically impossible due to intricate interphase interactions dictated by packing geometry and surface characteristics. In addition, it is necessary to model the chemical absorption of acid gases into MDEA. There are mainly two approaches for modeling of gas absorption in the literature. The first assumes thermodynamic equilibrium for both streams leaving each stage and its idealization is compromised by introducing HETP (height equivalent to a theoretical plate) [10]. This parameter has to incorporate many other parameters affecting the operation of the column, including packing type, size and material. The so called rate-based approach, which appears more realistic, directly considers mass and heat transfer [11-13]. In most of these studies film or penetration theories are applied for prediction of the rate of mass transfer in liquid and gas. Two-film theory, which has gained more acceptance and understanding, considers that molecular diffusion occurs solely in two thin adjacent films near the interphases and there exists no concentration gradient outside this film to a high degree of mixing in the bulk [10]. The Accuracy of film theory model depends upon good estimation of film thickness. Also, multicomponent mixtures are characterized by several diffusion coefficients related to different component binary pairs, and therefore, the film thickness is different for each component.

In 1972, Zogg investigated the performance of structured packings equipped with Sulzer BX and Sulzer BY gauze packings [14]. A similar model for mass transfer in gauze packings was proposed by Bravo et al. [1] and then by Fair and Bravo [15], and Rocha et al. [1, 3, 4], to include the expected incomplete surface wetting for structured packings of the corrugated sheet type. They considered the gas flow in structured packings as passing through a series of wettedwall columns with the dimensions related to the actual angle and size of the corrugations. Olujic [5,7] proposed a model which represents the packings as a bundle of wetted wall channels with the characteristic triangular cross-section. In some other studies liquid motion is approximated by the film flow over an inclined surface [16, 17]. A fairly comprehensive literature survey about structured packings was done by Shilkin et al. [9].

In 2004, Ludovic Raynal worked on determination of mass transfer characteristics of co-current two-phase flow within structured packing. Both physical and chemical meth- ods were used to determine the mass transfer performance of structured packing for gas-liquid absorption under co-current downward operation [18]. Absorption of nitrogen oxides in aqueous solutions in a structured packing pilot column was investigated by de Paivain in 2005. This study deals with the absorption of dilute nitrogen oxides $\mathrm{NO}_{\mathrm{x}}$ into aqueous solutions of hydrogen peroxide and of sodium hydroxide at atmospheric pressure. A pilot column filled with the structured metallic packing Optiflow ${ }^{\text {TM }}$ was employed [19]. Thin film flow over structured packings was also studied by Prashant Valluri in 2005. The model describes the dynamic evolution of waves on laminar falling wavy films at low to moderate Reynolds numbers over corrugated surfaces [20]. Recently, in 2007, a multi-scale approach was used by Raynal for CFD calculations of gas-liquid flow within a large-size column equipped with structured packing. This study focuses on the CFD modeling of the two-phase flow within a complex geometry. It first considers liquid-wall and liquid-gas interactions on a small scale via two-phase flow calculations using the (volume of fluid) VOF method. Second, the latter results are used in three-dimensional calculations run on a mesoscale corresponding to a periodic element representative of the real packing geometry. Last, those results are further used on a large scale in three-dimensional calculations with a geometry corresponding to a complete column [21].

As can be seen from the above discussion, there is still controversy in the selection of the best approach for modeling the absorption of acid gases into MDEA in the structured packed column. The first choice is to consider all the realistic phenomena in the process. For instance, one can consider turbulency in the gas and liquid, and also take different values for diffusivity of species in the liquid and consider that the entire surface is not wetted with the liquid. In this case it is very hard to localize the boundaries between liquid and gas and almost impossible to write equations of mass, momentum and energy balances. The second choice is to simplify the process, as is the case in the Shilkin model, in which the flow of liquid and gas is assumed to be laminar. It should be noticed that taking even these idealistic conditions usually results in good and valuable knowledge of the process and paves the way for reliable design on an industrial scale. In the present paper geometric calculations, phase boundary localizations and conditions used in the modeling of Shilkin et al. [9] are applied for mathematical modeling of chemical absorption of acid gases into MDEA in a structured packed bed. The geometric calculations regarding the packings as well as velocity equations for gas and liquid are similar to those utilized in Shilkin's work.

\section{GEOMETRIC CHARACTERISTICS AND FLUID FLOW IN STRUCTURED PACKINGS}

A complicated liquid flow over a packing surface which is made by corrugated sheets (Fig. 1) manufactured from 


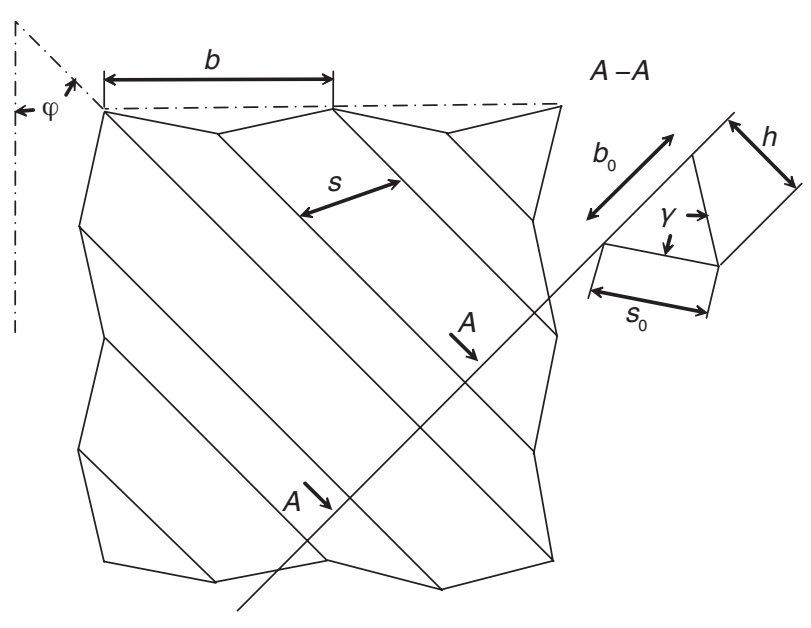

Figure 1

Geometry structure of a corrugated sheet, adopted from Reference [9].

gauze, metal, ceramics or plastics is simplified to a laminar film flow. This simplification lets us localize phase boundaries and specify boundary conditions. Therefore, continuum mechanics equations of flow can be solved for the system.

Typical corrugated sheet structured packings are composed of a number of segments perpendicular to each other to produce the mixing effects for both gas and liquid at each transition from one packing segment to another. The packing segment can be visualized as a set of channels formed from counter-course installation of corrugated sheets. The detail of the shape of a segment of a typical corrugated sheet structured packing is given elsewhere [9].
Channels formed by corrugated sheets cross each other at an angle of $\varphi$ and are assumed to have identical cross-section areas. Each channel is formed by the two wall sides $s_{0}$ and one open side $b_{0}$, which faces a neighboring channel and is shared between the two channels [17].

Based on previous studies [7, 9, 15], we assume that:

- the gas flow through a packing segment can be approximated by a flow through a bundle of channels with dimensions derived from the corrugation geometry of Figure 1;

- channels are round;

- the gas and liquid flows in the channels are laminar and fully developed;

- under influence of gravity (as in this case), liquid generally tends to move in the form of laminar films at the minimal angle with the column axis, corresponding to the gravity flow angle $\alpha$ (see Fig. 2);

- gas and liquid are ideally mixed at certain points dictated by geometric configuration. These points, which are called mixing points, will be discussed in the following sections. For all channels, the film thickness is the same. This means that any radial maldistribution is neglected.

The inner diameter of a channel is set equal to the hydraulic diameter of the corresponding triangular channel:

$$
d_{h}=\frac{b_{0} h}{s_{0}}
$$

Mixing points are assumed in each channel for liquid and gas where they are fully mixed because of abrupt changes in gas and liquid flow. Shilkin assumed the length of the undistributed laminar flow to be equal to an average channel length in a packing segment. These mixing points are calculated separately for each phase [9].

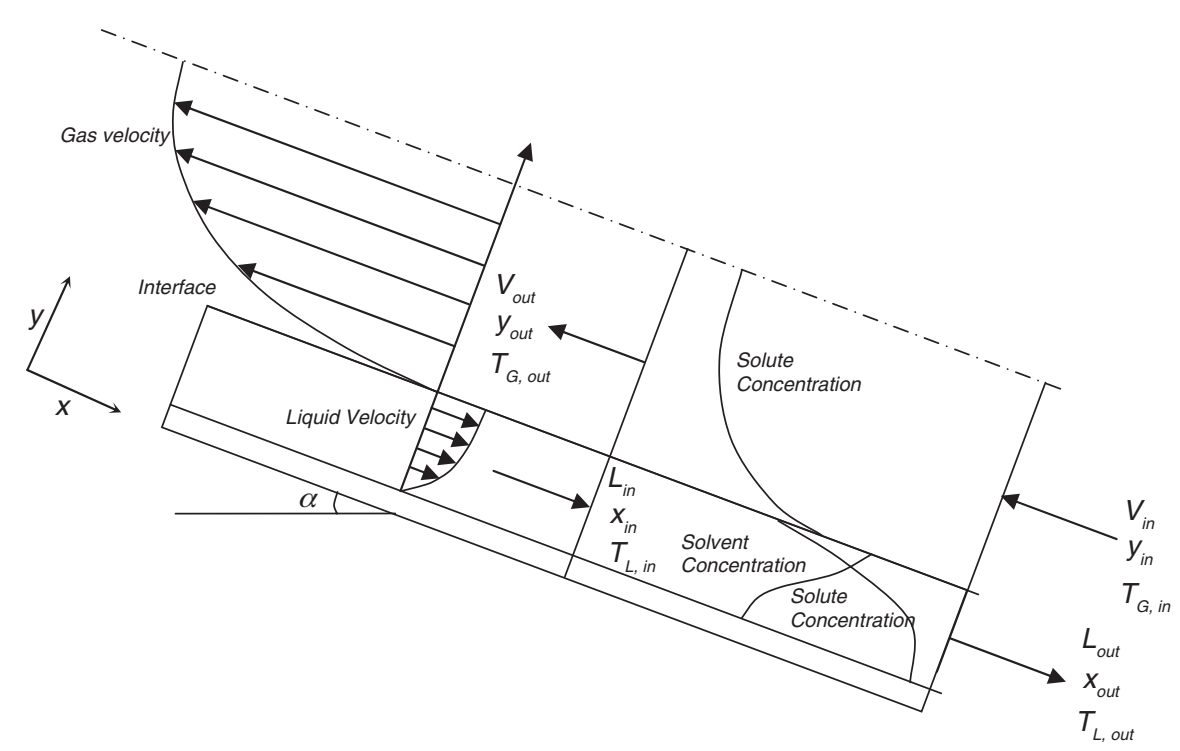

Figure 2

Schematic of flow of liquid and gas, and concentration distribution in the channels. 
$z_{L}=\frac{b_{0}}{2 \sin (\gamma / 2) \sin (\arcsin (\sin \varphi \cos (\arctan (\cos \varphi \cot (\gamma / 2)))))}(2)$

Total channel length is given by the following relation:

$$
\begin{gathered}
B_{i}=\sqrt{D_{p a c}^{2}-(h(n-2(i-1)))^{2}} \\
l_{i}=\frac{2 B_{i} L}{b_{0}}, i=1, \ldots, n \\
n=\left[\frac{D_{p a c}}{h}\right], k=\left\{\frac{1}{2} n\right\}
\end{gathered}
$$

By [ ] we mean nearest smaller integer number and by \{\} we mean rounded off to the nearest bigger integer number.

The average channel length is given for even and odd $n$ as follows:

$$
\begin{gathered}
z_{G}=\frac{2 L \sum_{i=1}^{k} B_{i}}{2 \cos \varphi \sum_{i=1}^{k} B_{i}+k\left(2 L \sin \varphi-b_{0}\right)}, n \text { is even } \\
z_{G}=\frac{2 L\left(2 \sum_{i=1}^{k} B_{i}+B_{k}\right)}{2 \cos \varphi\left(2 \sum_{i=1}^{k} B_{i}+B_{k}\right)+(2 k-1)\left(2 L \sin \varphi-b_{0}\right)},
\end{gathered}
$$

The total inner surface of the channels comprising a packing segment is related to the packing geometric (installed) area $S_{t}$, whereas their wetted surface is related to the packing effective (wetted) mass transfer area $S_{e}$. However, both surfaces are assumed to be the same.

$$
\begin{aligned}
& S_{t}=a_{t} \frac{\pi D_{p a c}^{2}}{4} L \\
& S_{e}=a_{e} \frac{\pi D_{p a c}^{2}}{4} L
\end{aligned}
$$

Hydraulic boundary conditions for liquid, gas and the interphase are considered as follows:

On the sheet wall (liquid):

$$
y=0, \quad u_{L}=0
$$

On the interphase:

$$
y=\delta, \quad u_{L} \frac{\partial u_{L}}{\partial y}=u_{G} \frac{\partial u_{G}}{\partial y}
$$

On the channel symmetry axis:

$$
y=R_{h}=\frac{d_{h}}{2}, \quad \frac{\partial u_{G}}{\partial y}=0
$$

By application of the system of Navier-Stokes equations in the film flow approximation (Fig. 2) and using necessary boundary conditions, the following parabolic form for velocity distribution is found [9]:

$$
u_{p}=A_{p} y^{2}+B_{p} y+C_{p}, \quad p=L, G
$$

The coefficients of Equation (13) can be found by applying boundary conditions and conservation of momentum and mass concepts in the following form:

$$
A_{L}=\frac{\Delta P+\rho_{L} g \sin \alpha}{2 \mu_{L}}
$$

$$
A_{G}=\frac{\Delta P+\rho_{G} g \sin \alpha}{2 \mu_{G}}
$$

$$
B_{G}=-2 A_{G} R_{h}
$$

$$
C_{L}=0
$$

$$
\mu_{L}\left(2 A_{L} \delta+B_{L}\right)=\mu_{L}\left(2 A_{G} \delta+B_{G}\right)
$$

$$
q_{G}=w_{G}\left(A_{G} \frac{R_{h}^{3}-\delta^{3}}{3}+B_{G} \frac{R_{h}^{2}-\delta^{2}}{3}+C_{G}\left(R_{h}-\delta\right)\right)
$$

Also, the following expression for the determination of the liquid film thickness $\delta$ can be derived:

$$
\begin{aligned}
& \frac{g w_{G} \delta\left(R_{h}-\delta\right)^{2}\left(\rho_{L}-\rho_{G}\right)\left(3 \mu_{G} \delta+4 \mu_{L}\left(R_{h}-\delta\right)\right) \sin \alpha}{6 \mu_{G} \mu_{L}\left(3 R_{h}-\delta\right)} \\
& +\frac{q_{L} w_{G}\left(\delta-R_{h}\right)\left(3 \mu_{G} \delta\left(2 R_{h}-\delta\right)+2 \mu_{L}\left(R_{h}-\delta\right)^{2}\right)}{\mu_{G} w_{L} \delta^{2}\left(3 R_{h}-\delta\right)} \\
& -q_{G}=0
\end{aligned}
$$

\section{HEAT AND MASS TRANSFER}

The liquid consists of water $\left(\mathrm{H}_{2} \mathrm{O}\right)$, MDEA, and dissolved $\mathrm{CO}_{2}$ and $\mathrm{H}_{2} \mathrm{~S}$, and ion species such as hydronium $\left(\mathrm{H}_{3} \mathrm{O}^{+}\right)$, hydroxide $\left(\mathrm{OH}^{-}\right)$, bicarbonate $\left(\mathrm{HCO}_{3}{ }^{-}\right)$, carbonate $\left(\mathrm{CO}_{3}{ }^{2-}\right)$, bisulfide $\left(\mathrm{HS}^{-}\right)$, sulfide $\left(\mathrm{S}^{2-}\right)$ and protonated MDEA $\left(R_{2} R^{\prime} N H^{+}\right)$. These ions are produced from the following equilibrium reactions:

Water Dissociation:

$$
2 \mathrm{H}_{2} \mathrm{O} \stackrel{K_{\mathrm{H}_{2} \mathrm{O}}}{\rightleftarrows} \mathrm{H}_{3} \mathrm{O}^{+}+\mathrm{OH}^{-}
$$


Bicarbonate Formation:

$$
2 \mathrm{H}_{2} \mathrm{O}+\mathrm{CO}_{2} \stackrel{K_{\mathrm{HCO}_{3}^{-}}}{\rightleftarrows} \mathrm{H}_{3} \mathrm{O}^{+}+\mathrm{HCO}_{3}^{-}
$$

Carbonate Formation:

$$
\mathrm{H}_{2} \mathrm{O}+\mathrm{HCO}_{3}^{-} \stackrel{K_{\mathrm{CO}_{3}^{-}}}{\rightleftarrows} \mathrm{H}_{3} \mathrm{O}^{+}+\mathrm{CO}_{3}^{--}
$$

Bisulfide Formation:

$$
\mathrm{H}_{2} \mathrm{O}+\mathrm{H}_{2} \mathrm{~S} \stackrel{K_{\mathrm{HS}^{-}}}{\rightleftarrows} \mathrm{H}_{3} \mathrm{O}^{+}+\mathrm{HS}^{-}
$$

Sulfide Formation:

$$
\mathrm{H}_{2} \mathrm{O}+\mathrm{HS}^{-} \stackrel{K_{\mathrm{S}^{--}}}{\rightleftarrows} \mathrm{H}_{3} \mathrm{O}^{+}+\mathrm{S}^{--}
$$

MDEA protonation:

$$
\mathrm{H}_{2} \mathrm{O}+R_{2} R^{\prime} N H^{+} \stackrel{K_{\mathrm{MDEAH}^{+}}}{\rightleftarrows} \mathrm{H}_{3} \mathrm{O}^{+}+R_{2} R^{\prime} N
$$

The reaction rate of amine with carbon dioxide is expressed as:

$$
-r_{\mathrm{MDEA}-\mathrm{CO}_{2}}=k_{I} C_{B_{2}}\left(C_{A_{1}}-\frac{C_{E_{2}}}{K_{\mathrm{HCO}_{3}^{-}} C_{\mathrm{OH}^{-}}}\right)
$$

The reaction of $\mathrm{CO}_{2}$ with water or bicarbonate formation is neglected due to the low rate constant and other reactions are assumed to be instantaneous. The equilibrium constants and rate of alkanolamine reactions with the acid gases $\mathrm{H}_{2} \mathrm{~S}$ and $\mathrm{CO}_{2}$ are documented by Austgen (1989) and Glasscock (1990), respectively. The concentrations of $\mathrm{H}_{2} \mathrm{O}, \mathrm{H}_{3} \mathrm{O}^{+}$, $\mathrm{CO}_{3}{ }^{2-}$ and $\mathrm{S}^{2-}$ in the liquid film are set equal to their respective liquid equilibrium concentrations and invariant across the liquid film. Based on the above discussion, it is possible to write six differential equations for the six species $\mathrm{CO}_{2}$ $\left(A_{1}\right), \mathrm{H}_{2} \mathrm{~S}\left(A_{2}\right)$, MDEA $\left(B_{2}\right), \mathrm{HCO}_{3}^{-}\left(E_{2}\right), \mathrm{HS}^{-}\left(E_{3}\right)$ and $\operatorname{MDEAH}^{+}\left(F_{2}\right)$ in the liquid. The symbols in parenthesis are introduced to simplify the notations. The six differential equations are given by:

$\mathrm{CO}_{2}$ :

$$
\frac{\partial^{2} C_{A_{1}}}{\partial y^{2}}=-\frac{1}{D_{A_{1}}}\left(r_{B_{2}-A_{1}}+u_{L}(y) \frac{\partial C_{A_{1}}}{\partial x}\right)
$$

\section{$\mathrm{H}_{2} \mathrm{~S}:$}

$$
\frac{\partial^{2} C_{A_{2}}}{\partial y^{2}}=\frac{1}{D_{A_{2}}}\left(r_{B_{2}-A_{1}}+u_{L}(y)\left(\frac{\partial C_{A_{2}}}{\partial x}-\frac{\partial C_{B_{2}}}{\partial x}\right)+D_{B_{2}} \frac{\partial^{2} C_{B_{2}}}{\partial y^{2}}\right)
$$

MDEA:

$$
\begin{aligned}
& \frac{\partial^{2} C_{B_{2}}}{\partial y^{2}}=\frac{1}{C_{A_{2}} k_{A_{2}-B_{2}}} \\
& \left(2\left(1+C_{E_{3}}\right) \frac{\partial^{2} C_{E_{3}}}{\partial y^{2}}+C_{E_{3}} \frac{\partial^{2} C_{E_{2}}}{\partial y^{2}}+C_{E_{2}} \frac{\partial^{2} C_{E_{3}}}{\partial y^{2}}+2 \frac{\partial C_{E_{2}}}{\partial y} \frac{\partial C_{E_{3}}}{\partial y}\right)(30) \\
& +\frac{1}{C_{A_{2}}}\left(-2 \frac{\partial C_{A_{2}}}{\partial y} \frac{\partial C_{B_{2}}}{\partial y}-C_{B_{2}} \frac{\partial^{2} C_{A_{2}}}{\partial y^{2}}\right)
\end{aligned}
$$$$
\mathrm{HCO}_{3}^{-} \text {: }
$$

$$
\frac{\partial^{2} C_{E_{2}}}{\partial y^{2}}=-\frac{1}{\bar{D}}\left(r_{B_{2}-A_{1}}+u_{L}(y) \frac{\partial C_{E_{2}}}{\partial x}\right)
$$

$\mathrm{HS}^{-}$:

$\frac{\partial^{2} C_{A_{2}}}{\partial y^{2}}=\frac{1}{\bar{D}}\left(-r_{B_{2}-A_{1}}+u_{L}(y)\left(\frac{\partial C_{E_{3}}}{\partial x}+\frac{\partial C_{B_{2}}}{\partial x}\right)-D_{B_{2}} \frac{\partial^{2} C_{B_{2}}}{\partial y^{2}}\right)$

$\mathrm{MDEAH}^{+}$:

$\frac{\partial^{2} C_{F_{2}}}{\partial y^{2}}=\frac{1}{\bar{D}}\left(u_{L}(y)\left(\frac{\partial C_{F_{2}}}{\partial x}+\frac{\partial C_{B_{2}}}{\partial x}\right)-D_{B_{2}} \frac{\partial^{2} C_{B_{2}}}{\partial y^{2}}\right)$

It should be noticed that no reaction is considered in the gas, and thus governing partial differential equations of mass transfer for nonreacting species in liquid and all presented components in the gas are given in the following equations:

$$
\begin{aligned}
& \frac{\partial^{2} C_{i, L}}{\partial y^{2}}=\frac{1}{D_{i, L}} u_{L}(y) \frac{\partial C_{i, L}}{\partial x} \\
& \frac{\partial^{2} C_{i, G}}{\partial y^{2}}=\frac{1}{D_{i, G}} u_{G}(y) \frac{\partial C_{i, G}}{\partial x}
\end{aligned}
$$

The concentration of the hydroxide ion may be related to the concentrations of MDEA, MDEAH ${ }^{+}$and $\mathrm{H}_{2} \mathrm{O}$ by the equilibrium relation:

$$
C_{\mathrm{OH}^{-}}=\frac{K_{\mathrm{H}_{2} \mathrm{O}} C_{\mathrm{MDEA}} C_{\mathrm{H}_{2} \mathrm{O}}}{K_{\mathrm{MDEAH}^{+}} C_{\mathrm{MDEAH}^{+}}}
$$

In the inlet of each segment, bulk concentrations of $\mathrm{H}_{2} \mathrm{O}$, $\mathrm{H}_{3} \mathrm{O}^{+}, \mathrm{CO}_{3}{ }^{2-}$ and $\mathrm{S}^{2-}$ are calculated by the method of Barreau et al. [22]. Concentrations of these components are either too low, such as $\mathrm{H}_{3} \mathrm{O}^{+}, \mathrm{CO}_{3}{ }^{2-}$ and $\mathrm{S}^{2-}$, or too high, such as $\mathrm{H}_{2} \mathrm{O}$, which are reasonably assumed to be invariant until we reach the next segment. 
The diffusivity of $\mathrm{CO}_{2}$ in the reactive solution was approximated by the $\mathrm{N}_{2} \mathrm{O}$ analogy proposed by Versteeg and van Swaaij [23], the diffusivity of $\mathrm{H}_{2} \mathrm{O}$ in the solution was approximated by $1.02 \mathrm{D}_{\mathrm{CO}_{2}}$ using the Wilke-Chang formula [24], and the alkanolamine diffusivity was approximated using the modified Stokes-Einstein equation as proposed by Glasscock [25].

The ion diffusion coefficient $D_{i}$ is assumed to be invariant in the liquid film. Regardless of the size, the charged species diffuse at a rate that maintains the solution electrically neutral. Thus, $D_{i}$, for any charged species, depends on the concentrations of all charged species present. In this study, to preserve electro-neutrality the diffusion coefficients of all ions are set equal so Equations (31-33) can be used. The diffusivities of all ions are set equal to a molar average diffusion coefficient, $\bar{D}$ :

$$
\bar{D}_{i}=\frac{\sum_{i} x_{i}}{\sum_{i} \frac{x_{i}}{D_{i}}}
$$

where $\bar{D}_{i}$ and $x_{i}$ are the intrinsic diffusivity and the mole fraction of ion $i$, respectively. The heat transfer equations for gas and liquid are:

$$
\begin{aligned}
& k_{L} \frac{\partial^{2} T}{\partial y^{2}}=\frac{\partial}{\partial x}\left(u_{L}(y) \frac{\rho}{\bar{M}} \sum x_{i} \bar{h}_{i}^{l i q}\right), \\
& \alpha_{G} \frac{\partial^{2} T}{\partial y^{2}}=u_{G}(y) \frac{\partial T_{G}}{\partial x}
\end{aligned}
$$

where $\bar{h}_{i}^{\text {liq }}$ is the partial molar enthalpy of component $i$ in liquid. This term can be expressed in terms of an ideal solution molar enthalpy, $h_{i}^{i s}$, and an excess molar enthalpy, $h_{i}^{\text {ex }}$, according to:

$$
\bar{h}_{i}^{l i q}(T, P, x)=h_{i}^{i s}(T, P)+h_{i}^{e x}(T, P, x)
$$

Neglecting the effect of pressure, the ideal solution molar enthalpy for solvents such as water and alkanolamine is given by:

$$
\begin{aligned}
& h_{i}^{i s}(T, P) \approx h_{i}^{i s}\left(T, P_{\mathrm{H}_{2} \mathrm{O}}^{\text {sat }}\right)=\Delta h_{i}^{f, i g}\left(T^{r e f}\right) \\
& +\int_{T^{\text {ref }}}^{T} C_{P, i}^{i g}(T) d T-R T^{2} \frac{\partial \ln \left(h_{i, \mathrm{H}_{2} \mathrm{O}}\right)}{\partial T}
\end{aligned}
$$

where $\Delta h_{i}^{l v}(T)$ is the heat of vaporization of solvent evaluated at the system temperature.
For molecular solutes such as $\mathrm{CO}_{2}$ and $\mathrm{H}_{2} \mathrm{~S}$, the corresponding ideal solution molar enthalpy is given by:

$$
\begin{aligned}
& h_{i}^{i s}(T, P) \approx h_{i}^{i s}\left(T, P_{\mathrm{H}_{2} \mathrm{O}}^{s a t}\right)=\Delta h_{i}^{f, i g}\left(T^{r e f}\right) \\
& +\int_{T^{\text {ref }}}^{T} C_{P, i}^{i g}(T) d T-R T^{2} \frac{\partial \ln \left(h_{i, \mathrm{H}_{2} \mathrm{O}}\right)}{\partial T}
\end{aligned}
$$

The ideal solution molar enthalpy for ionic species is given by:

$$
h_{i}^{i s}(T, P) \approx \Delta h_{i}^{f, a q}(298.15)+C_{P, i}(T-298.15)
$$

where $\Delta h_{i}^{f, a q}$ is the heat of formation of an ion, $i$, at infinite dilution in water. The excess Gibbs free energy measures the deviation of the system from ideality. All other thermodynamic excess properties can be derived from the excess Gibbs free energy relations. Since this property is related to the species activity coefficients the excess molar enthalpies of species $i$, $h_{i}^{e x}$, have a similar relationship. This relationship is given by:

$$
h_{i}^{e x}=-R T^{2}\left(\frac{\partial \ln \gamma_{i}}{\partial T}\right)_{x}
$$

In Equation (43) it is assumed that pressure has a negligible effect on the excess molar enthalpy. The activity coefficients of all species are computed from the electrolyte-NRTL model at specified system temperature, acid gas loadings and alkanolamine initial percent. The excess molar enthalpies of all species are determined by numerically differentiating the activity coefficient of each species with respect to temperature at fixed species mole fractions.

Boundary conditions are formulated as follows [9]:

At the entrance of liquid:

$$
x=0, \quad C_{L}=C_{L}^{i n}, \quad T_{L}=T_{L}^{i n}
$$

At the entrance of gas:

$$
x=L, \quad C_{G}=C_{G}^{i n}, \quad T_{G}=T_{G}^{i n}
$$

At the wall (adiabatic and non-permeable):

$$
y=0, \quad \frac{\partial C_{L}}{\partial y}=0, \quad \frac{\partial T_{L}}{\partial y}=0
$$

At the channel symmetry axis:

$$
y=R_{h}, \quad \frac{\partial C_{G}}{\partial y}=0, \quad \frac{\partial T_{\mathrm{G}}}{\partial y}=0
$$


At the phase interface (thermodynamic equilibrium, mass and energy conservation conditions):

$$
\begin{aligned}
& y=\delta, \quad C_{G}=\left[K_{i}\right] C_{L} \quad T_{L}=T_{G}, \\
& {\left[D_{L}\right] \frac{\partial C_{L}}{\partial y}=\left[D_{G}\right] \frac{\partial C_{G}}{\partial y}+\left.r_{L}\right|_{y=\delta}} \\
& \lambda_{L} \frac{\partial T_{\mathrm{L}}}{\partial y}=\lambda_{L} \frac{\partial T_{\mathrm{L}}}{\partial y}+\left(\Delta H_{r x n}\right)^{T}\left[D_{L}\right] \frac{\partial \mathrm{C}_{\mathrm{L}}}{\partial y}
\end{aligned}
$$

$\left.r_{L}\right|_{y=\delta}$ is the rate of surface reaction and is zero for all components other than $\mathrm{H}_{2} \mathrm{~S}$, which has an instantaneous reaction with amine.

The surface reaction terms appearing in Equation (48) are obtained from stoicheiometry as follows:

$$
\left.r_{A_{2}}\right|_{z=0}=\left.r_{B_{2}}\right|_{z=0}=\left.D_{B_{2}} \frac{d C_{B_{2}}}{d z}\right|_{z=0}
$$

Film concentration distribution is not known at first and is calculated in a trial-and-error procedure.

Reynolds numbers for gas and liquid streams are calculated in the following form:

$$
\begin{gathered}
\operatorname{Re}_{G}=\frac{\dot{m}_{G} L d_{h}}{S_{t} \sin \alpha\left(R_{h}-\delta\right) \mu_{G}} \\
\operatorname{Re}_{L}=\frac{\dot{m}_{L} L d_{h}}{S_{e} \sin \alpha \delta \mu_{L}}
\end{gathered}
$$

\section{METHOD OF SOLUTION}

For the known parameters of the column $\left(D_{p}, \gamma, \varphi\right.$, etc. $)$ an arbitrary height was assigned for the column. With known inlet conditions, the following sequential steps were taken to solve Equations (28) through (48) for the assigned value of the height:

- All geometric dimensions of the column were calculated by using Equations (1) through (9).

- Having inlet gas and liquid information and guessing the exiting gas stream, overall material and energy balances for the column will provide the exiting liquid stream. After this, the column height starting from the bottom was divided into segments of 0.183 meters. The following calculations were carried out for all the segments starting with the first segment for which (at the bottom of the column) the conditions of entering gas and exiting liquid are known.

- The space of the segment was discretized in and directions and mass balance Equations (28) through (35), which included velocity distribution, Equations (13-20), and energy balance, Equation (38), with their boundary conditions of (44) through (48) were applied in each point of discretized space.
- The rate of reaction at the surface for $\mathrm{H}_{2} \mathrm{~S}$ in Equation (48) was set equal to zero for the first iteration.

- The nonlinear algebraic equations resulting from discretization in step 3 were solved by Newton's global convergence method. The advantage of this method is that it is not too sensible to the initial guess. The results of these equations give temperature and concentration distribution over the segment. Instead of setting the rate of reaction equal to zero for $\mathrm{H}_{2} \mathrm{~S}$ at the surface, after the first iteration the following two steps were taken to calculate it.

- Concentration distribution calculated in step 5 gives the new value for the rate of surface reaction using Equation (49). This rate is compared with what is guessed in step 4 and its iterations are repeated until the difference between new and old values of the rate varies within a specified range.

- Temperature and concentration of exiting streams from one segment are the inlet information for the next segment. A uniform distribution is assumed in the direction for each segment.

- This procedure is repeated from the bottom to the top of the column. When the calculation is carried out for the last segment (top of the column) the conditions of the exiting gas stream will be calculated. This information was also guessed in step 2. Comparing calculated and guessed information about the exiting gas stream indicates whether repeating iteration is necessary or not for that assigned height.

- The assigned value of the height of the column was changed and all the steps were carried out. The change in value of height and carrying out the calculations were repeated until a reasonable agreement was noticed between estimated and calculated information for the exiting gas stream in the tray column.

\section{RESULTS AND DISCUSSIONS}

Montz-Pak A3-500 packings are used for solution of the mathematical modeling of acid gas absorption. The geometric specifications of structured packing and model parameters are listed in Table 1.

TABLE 1

Geometric characteristics and model parameters of the bed, Montz-Pak A3-500 packings

\begin{tabular}{l|c|c|c}
\hline$a_{t}\left(\mathrm{~m}^{2} / \mathrm{m}^{3}\right)$ & 500 & $d_{h}(\mathrm{~m})$ & 0.0045 \\
$\varepsilon(-)$ & 0.95 & $R_{h}$ & 0.00225 \\
$h(\mathrm{~m})$ & 0.006 & & 66.5 \\
$b_{0}(\mathrm{~m})$ & 0.009 & $z_{L}(\mathrm{~m})$ & 0.0228 \\
$s_{0}(\mathrm{~m})$ & 0.0075 & $z_{G}(\mathrm{~m})$ & 0.2024 \\
$L(\mathrm{~m})$ & 0.183 & $S_{t}\left(\mathrm{~m}^{2}\right)$ & 602.293 \\
$\gamma\left(^{\circ}\right)$ & 74 & $S_{e}\left(\mathrm{~m}^{2}\right)$ & 602.293 \\
$\varphi\left(^{\circ}\right)$ & 30 & $D_{p}(\mathrm{~m})$ & 2.895 \\
\hline
\end{tabular}


TABLE 2

Specifications of column with sieve trays

\begin{tabular}{c|c|c|c|c|c|c|c}
\hline Diameter $(\mathrm{m})$ & Height $(\mathrm{m})$ & No. of trays & Bubble area $\left(\mathrm{cm}^{2}\right)$ & Active area $\left(\mathrm{cm}^{2}\right)$ & Diameter of holes $(\mathrm{cm})$ & Weir height $(\mathrm{cm})$ & Tray spacing $(\mathrm{cm})$ \\
\hline 2.895 & 16.46 & 20 & 3393.5 & 42411.96 & 0.5556 & 14.1 & 80 \\
\hline
\end{tabular}

TABLE 3

Conditions of feed gas (sour), lean amine, sweet gas and rich amine streams

\begin{tabular}{|c|c|c|c|c|c|c|c|c|}
\hline & $\% \mathrm{H}_{2} \mathrm{~S}$ & $\% \mathrm{CO}_{2}$ & $\% \mathrm{CH}_{4}$ & $\% \mathrm{H}_{2} \mathrm{O}$ & $\%$ MDEA & $F(\mathrm{kmol} / \mathrm{h})$ & $T(\mathrm{~K})$ & Pressure $(\mathrm{kPa})$ \\
\hline Sour gas & 3.85 & 6.41 & 89.71 & 0.03 & - & 635.40 & 294.1 & 7401 \\
\hline Lean amine & - & - & - & 91.89 & 8.11 & 1606.8 & 350 & 7506 \\
\hline Sweet gas & $4 \mathrm{ppm}$ & 2.55 & 97.16 & 0.29 & - & 565.55 & 329.4 & 7506 \\
\hline Rich amine & 1.46 & 1.57 & 1.22 & 87.98 & 7.77 & 1676.65 & 327.1 & 7401 \\
\hline
\end{tabular}

Since there was no plant data for the absorption of acid gases by MDEA solution in a structured column with corrugated sheets on an industrial scale, therefore it was not possible to validate the model by plant data. We were forced to compare the performance of operating a sieve tray column (see Table 2) with a structured packed column. Different heights for the column were assigned, and according to the results of mathematical modeling of the structured packed column, it was found that at the height of 8.14, the degree of purification for acid gases in the structured packed bed and the operating sieve tray column is the same.

The performance of the modeled tray column was validated previously against operational data of an industrial sweetening absorption column.

A set of data for a $\mathrm{CO}_{2}-\mathrm{H}_{2} \mathrm{~S}-\mathrm{MDEA}$ absorber that is utilized in the solution of the model is shown in Table 3. The operating parameters are adjusted so that the flow of liquid and gas in the column are laminar.

Two Visual Basic programs were written to solve the governing equations of the model (1-9, 13-20 and 28-49). The task of the first program is to solve Equations (1-9) and Equations (13-20) and find the velocity distribution of gas and liquid in each part of the column. Having the velocity distribution in liquid and gas, the second program is used to solve governing equations relating to the mass and heat transfers (28-49). Both mentioned programs are implemented in a main program, so the second program takes advantage of the results of the first program for calculation of temperature and concentration distribution.

Figure 3 shows the velocity distribution resulting from the solution of hydrodynamic equations. Although the composition of the liquid differs from its correspondent value in Shilkin's paper due to the nature of the solvent and solute, the velocity distribution of liquid is in good agreement with results reported by Shilkin et al. Reynolds numbers for both liquid and gas streams are calculated according to Equations (50) and (51) at different parts of the structural column. The calculated Reynolds numbers are in the range of 100-200,

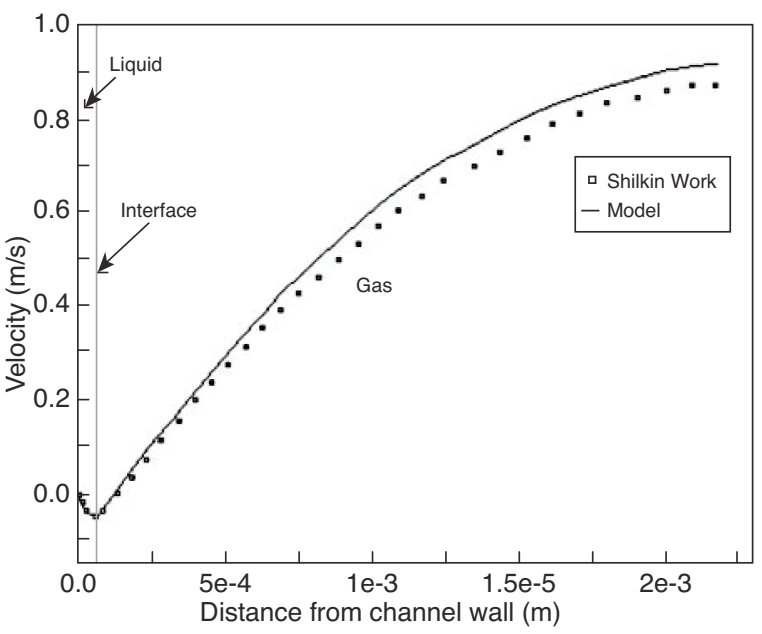

Figure 3

Calculated velocity $F_{L}=635.40 \mathrm{kmol} / \mathrm{h}, T_{L}=294.1 \mathrm{~K}$.

which are far from 2100, and therefore it can be fairly assumed that a laminar region prevails in gas and liquid streams.

Figure 4 shows that the composition profile of $\mathrm{H}_{2} \mathrm{~S}$ in the system exhibits three different regions depending on the location in the absorber. At the bottom of the absorber, region I, there is a little tendency for $\mathrm{H}_{2} \mathrm{~S}$ to get absorbed, as appears from the relatively moderate decrease in the mole fraction. At the middle stages, region II, there is a dramatic increase in the $\mathrm{H}_{2} \mathrm{~S}$ absorption rate, causing its mole fraction to approach the specified value. At the top of the absorber region III, it becomes extremely difficult to absorb $\mathrm{H}_{2} \mathrm{~S}$, although there is an appreciable driving force, as indicated from the difference between the equilibrium and actual compositions of $\mathrm{H}_{2} \mathrm{~S}$. The $\mathrm{H}_{2} \mathrm{~S}$ composition profiles show that the MDEA system has 


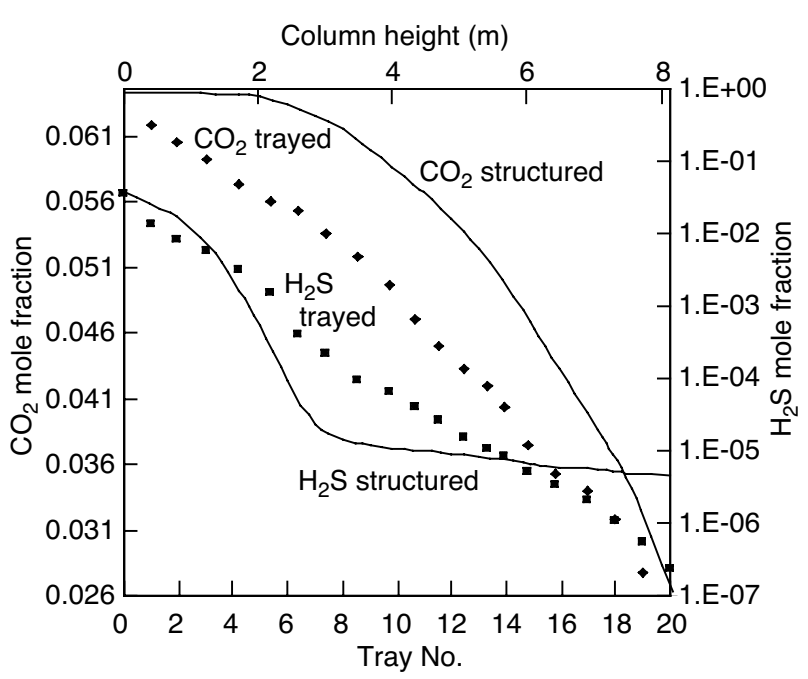

Figure 4

$\mathrm{H}_{2} \mathrm{~S}$ and $\mathrm{CO}_{2}$ mole fractions in gas versus height for a system of $\mathrm{CO}_{2}-\mathrm{H}_{2} \mathrm{~S}-\mathrm{MDEA}$ in structured packing and tray columns.

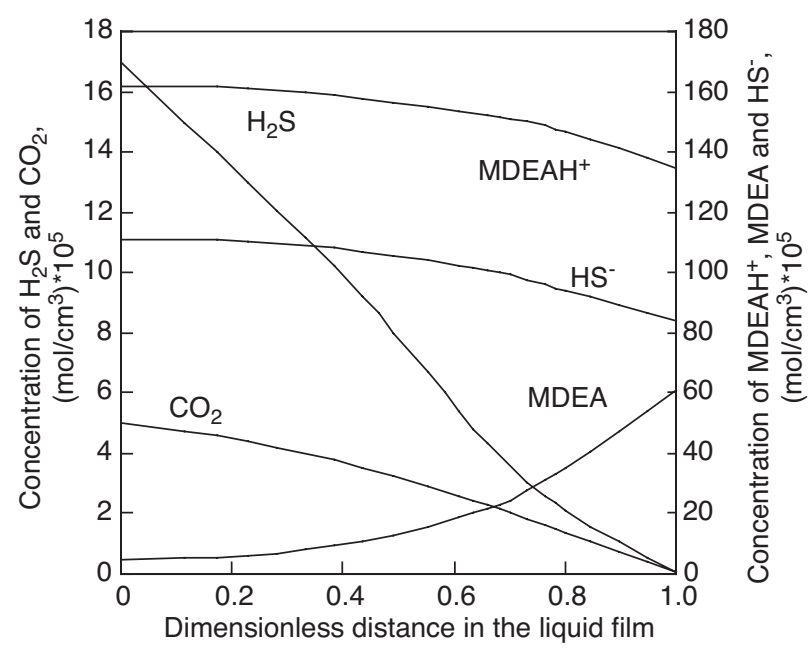

Figure 5

Typical concentration profiles in the liquid film versus dimensionless distance $(y / \delta)$ from the wall for distance $=3 \mathrm{~m}$ from the top of the column.

the best performance in regions II and I. However, in region III, the ability of MDEA to absorb $\mathrm{H}_{2} \mathrm{~S}$ becomes so poor that the composition of $\mathrm{H}_{2} \mathrm{~S}$ remains virtually unchanged. This is attributed to the presence of $\mathrm{CO}_{2}$, which strongly competes with $\mathrm{H}_{2} \mathrm{~S}$ in the consumption of amines, specially at the top of the absorber where the concentration of $\mathrm{CO}_{2}$ is much higher than $\mathrm{H}_{2} \mathrm{~S}$. Overall behavior in absorption of $\mathrm{H}_{2} \mathrm{~S}$ for both tray and structured columns are nearly the same. However, as Figure 4 shows, absorption of $\mathrm{H}_{2} \mathrm{~S}$ in the tray column is more difficult because no change in the mole fraction of $\mathrm{H}_{2} \mathrm{~S}$ is seen. Therefore, we can conclude that in a structured column we could achieve more $\mathrm{H}_{2} \mathrm{~S}$ purification by increasing the height of the column.

The composition profile of $\mathrm{CO}_{2}$ is also shown in Figure 4. As seen from this figure, the composition of $\mathrm{CO}_{2}$ is virtually constant at the bottom of the absorber, region I. The high concentration of the acid gases in addition to the scarcity of the amine in this region makes the competition between $\mathrm{CO}_{2}$ and $\mathrm{H}_{2} \mathrm{~S}$ to react with the amines extremely difficult. Due to the instantaneous reaction that occurs between $\mathrm{H}_{2} \mathrm{~S}$ and the amines, $\mathrm{H}_{2} \mathrm{~S}$ consumes most of the amines present, leaving a negligible amount to react with $\mathrm{CO}_{2}$. The competition continues to region II where the driving forces of both gases and the amine concentrations are higher. In this region the capacity of the amines is just enough to contain both gases. However, $\mathrm{H}_{2} \mathrm{~S}$, which has a faster tendency to react with the amines, continues to consume most of the amines until its absorption driving force diminishes. In region III, the $\mathrm{CO}_{2}$ driving force becomes too large, reducing further consumption of the amines by $\mathrm{H}_{2} \mathrm{~S}$. This makes extra purification of $\mathrm{H}_{2} \mathrm{~S}$ extremely difficult to achieve. As observed from this figure, the absorption driving force of both gases is minimized at the bottom of the absorber. In the middle of the tower, which corresponds to region II, the driving force of $\mathrm{H}_{2} \mathrm{~S}$ becomes higher. It then diminishes to a steady value all the way to the top of the absorber. For $\mathrm{CO}_{2}$, the driving force continues its increasing trend to the top of the absorber. Due to the extremely slow reaction of $\mathrm{CO}_{2}$ with MDEA, the absorption of $\mathrm{CO}_{2}$ does not start until $\mathrm{H}_{2} \mathrm{~S}$ reaches equilibrium. This explains why this system is the fastest to meet the specification of $\mathrm{H}_{2} \mathrm{~S}$. The trend of absorption of $\mathrm{CO}_{2}$ in the tray tower is similar to the structured column; however, the rate

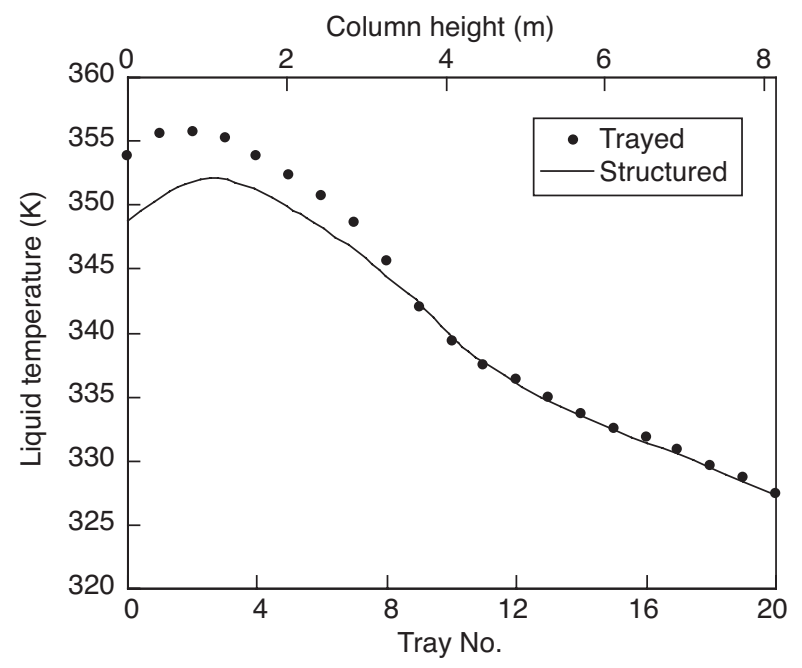

Figure 6

Liquid temperature versus height for $\mathrm{CO}_{2}-\mathrm{H}_{2} \mathrm{~S}$-amine towers. 
of absorption of $\mathrm{CO}_{2}$ becomes relatively linear from tray no. eight.

The liquid film concentration profiles of the reacting species in the $\mathrm{CO}_{2}-\mathrm{H}_{2} \mathrm{~S}-\mathrm{MDEA}$ system at distance $=3 \mathrm{~m}$ from the top of the column is shown in Figure 5. In this figure the distance is measured dimensionlessly as in which is the thickness of the liquid flowing film. These profiles confirm the boundary conditions of solute species, as is expected. The slope of the profile of $\mathrm{H}_{2} \mathrm{~S}$ is greater than $\mathrm{CO}_{2}$ and it can be related to instantaneous reaction between hydrogen sulfide and amine.

The temperature profile of the liquid is shown in Figure 6. The temperature profile of the $\mathrm{CO}_{2}-\mathrm{H}_{2} \mathrm{~S}$-MDEA system exhibits an inflated shape at the bottom of the absorber. The liquid temperature approaches the inlet gas temperature as we approach the top of the absorber. This system is fast to reach the inlet liquid temperature. This is attributed to the relatively negligible absorption of the acid gases by MDEA at the top of the absorber.

\section{CONCLUSION}

Absorption of the acid gases, $\mathrm{H}_{2} \mathrm{~S}$ and $\mathrm{CO}_{2}$, by methyl diethanol amine in a structured column was modeled. In the mathematical model, channels are assumed to be an identical cross-section in which the walls are wetted completely by liquid and the rest of the channels are occupied with the acid gases. A film theory as well as a non-equilibrium rate-based concept were applied to modeling the mass and heat transfer phenomena in both directions of flow of liquid and gas. With the mathematical model we were able to investigate concentration and temperature profiles along the bed. The temperature profile of the $\mathrm{CO}_{2}-\mathrm{H}_{2} \mathrm{~S}$-MDEA system exhibits a temporary growth at the bottom of the absorber. The driving forces for absorption of both gases are at their lowest values at the top of the absorber and some sections of the column practically do nothing. This behavior is stronger in the tray column than the structure column. Therefore, one might conclude that under the same conditions, the structured packed bed column in general has better performance. The fact is that due to the lack of experimental data for the structured column of commercial size we had to validate the model of this column against the model of a tray-type column which was validated by plant data. This lack of plant or experimental data could cast a shadow over our last conclusion. However, with this study we have taken the first step toward modeling a very complicated physical situation.

\section{ACKNOWLEDGMENT}

The financial support of the National Iranian Gas Company for this research is appreciated.

\section{REFERENCES}

1 Bravo J.L., Rocha J.A., Fair J.R. (1985) Mass transfer in gauze packing, Hydrocarb. Process. 91-95.

2 Nawrocki P.A., Xu Z.P., Chuang K.T. (1991) Mass transfer in structured packing, Can.J. Chem. Eng. 69, 1336-1343.

3 Rocha J.A., Bravo J.L., Fair J.R. (1993) Distillation columns containing structured packings: a comprehensive model for their performance. 1. Hydraulic models, Ind. Eng. Chem. Res. 32, 641-651.

4 Rocha J.A., Bravo J.L., Fair J.R. (1996) Distillation columns containing structured packings: a comprehensive model for their performance. 2. Mass-transfer model, Ind. Eng. Chem. Res. 35, 1660-1667.

5 Olujic Z. (1997) Development of a complete simulation model for predicting the hydraulic and separation performance of distillation columns equipped with structured packings, Chem. Biochem. Eng. Q. 11, 1,31-46.

6 Brunazzi E., Paglianti A. (1997) Liquid-film mass transfer coefficient in a column equipped with structured packing, Ind. Eng. Chem. Res. 36, 3792-3799.

7 Olujic Z. (1999) Effect of column diameter on pressure drop of a corrugated sheet structured packing, Chem. Eng. Res. Des. 77, 6, 505-510.

8 Billet R., Schultes M. (1999) Prediction of mass transfer columns with dumped and arranged packings: updated summary of the calculation method of Billet and Schultes, Trans. IChemE 77, 498-504.

9 Shilkin A., Kenig E.Y. (2005) A new approach to fluid separation modeling in the columns equipped with structured packings, Chem. Eng. J. 110, 87-100.

10 Taylor R., Krishna R. (1993) Multicomponent Mass Transfer, Wiley.

11 Al-Baghli N.A., Pruess S.A., Yesavage V.F., Selim M.S. (2001) A rate-based model for the design of gas absorbers for the removal of $\mathrm{CO}_{2}$ and $\mathrm{H}_{2} \mathrm{~S}$ using aqueous solutions of MEA and DEA, Fluid Phase Equilibr. 185, 31-43.

12 Taylor R., Kooijman H.A., Hung J.S. (1994) A second generation nonequilibrium model for computer simulation of multicomponent separation processes, Comput. Chem. Eng. 18, 205-217.

13 Higler A.P., Taylor R., Krishna R. (1998) Modeling of a reactive separation process using a non-equilibrium stage model, Comput. Chem. Eng. 22, S111-S118.

14 Zogg M. (1972) Stromungs- und Stoffaustauschuntersuchungen an der Sulzer-Gewebepackung, Ph.D. thesis, Technische Hochschule Zurich.

15 Fair J.R., Bravo J.L. (1990) Distillation columns containing structured packings, Chem. Eng. Prog. 19-29.

16 Johnstone H.F., Pigford R.L. (1942) Distillation in a wettedwall column, T. Am. Ind. Chem. Eng. 38, 25-50.

17 Kenig E.Y. (1997) Multicomponent multiphase film-like systems: a modeling approach, Comput. Chem. Eng. 21, S355-S360.

18 Raynal L., Ballaguet J.P., Barrere-Tricca C. (2004) Determination of mass transfer characteristics of co-current two-phase flow within structured packing, Chem. Eng. Sci. 59, 5395-5402.

19 de Paiva J.L., Kachan G.C. (2004) Absorption of nitrogen oxides in aqueous solutions in a structured packing pilot column, Chem. Eng. Process. 43, 941-948.

20 Valluri P., Matar O.K., Hewitt G.F., Mendes M.A. (2005) Thin flow over structured packings at moderate Reynolds numbers, Chem. Eng. Sci. 60, 1965-1975.

21 Raynal L., Royon-Lebeaud A. (2007) A multi-scale approach for CFD calculations of gas-liquid within large size column equipped with structured packing, Chem. Eng. Sci. 62, 7196-7204. 
22 Barreau A., Blanchon le Bouhelec1 E., Habchi Tounsi K.N., Mougin P., Lecomte F., (2006) Absorption of $\mathrm{H}_{2} \mathrm{~S}$ and $\mathrm{CO}_{2}$ in Alkanolamine Aqueous Solution: Experimental Data and Modeling with the Electrolyte-NRTL Model, Oil Gas Sci. Technol. - Rev. IFP 61, 3, 345-361.

23 Versteeg G., van Swaaij W. (1988) Solubility and Diffusivity of Acid Gases $\left(\mathrm{CO}_{2}, \mathrm{~N}_{2} \mathrm{O}\right)$ in Aqueous Alkanolamine Solutions, J. Chem. Eng. Data 33, 29-34.
24 Wilke C.R., Chang, P. (1955) AIChE J. 1, 264-270

25 Glasscock D.A. (1990) Modeling and Experimental Study of Carbon Dioxide Absorption into Aqueous Alkanolamines, $\mathrm{Ph} . \mathrm{D}$. Dissertation, The University of Texas at Austin, Austin, TX.

Final manuscript received in September 2008 Published online in April 2009 